University of Nebraska - Lincoln

DigitalCommons@University of Nebraska - Lincoln

10-1976

\title{
Electron Transmission Studies of the Negative Ion States of Substituted Benzenes in the Gas Phase
}

Kenneth D. Jordan

J.A. Michejda

Paul Burrow

Follow this and additional works at: https://digitalcommons.unl.edu/physicsburrow

Part of the Atomic, Molecular and Optical Physics Commons

This Article is brought to you for free and open access by the Research Papers in Physics and Astronomy at DigitalCommons@University of Nebraska - Lincoln. It has been accepted for inclusion in Paul Burrow Publications by an authorized administrator of DigitalCommons@University of Nebraska - Lincoln. 


\title{
Electron Transmission Studies of the Negative Ion States of Substituted Benzenes in the Gas Phase
}

\author{
K. D. Jordan, J. A. Michejda, and P. D. Burrow
}

Department of Engineering and Applied Science, Mason Laboratory, Yale University, New Haven, Connecticut 06520.

\begin{abstract}
Temporary negative ions of benzene, aniline, phenol, anisole, fluoro-, chloro-, and bromobenzene, formed in the gas phase by capture of electrons into the lowlying $\pi^{*}$ orbitals, are studied by means of electron transmission spectroscopy. The electron affinities are determined and their relative values are interpreted in terms of resonance and inductive effects.
\end{abstract}

Negative ions of aniline, phenol, anisole, fluoro-, chloro-, and bromobenzene may be formed in the gas phase by capture of impacting electrons into the low-lying $\pi^{*}$ orbitals. As in benzene and the alkyl-substituted benzenes, which we discussed in a previous communication, ${ }^{1}$ these anions are short lived and decay by ejecting the electron into the continuum in times of typically $10^{-14} \mathrm{~s}$ or less. The formation of these transient anions is observable as sharp variations or "resonances" in the cross section for electron scattering from the neutral molecules.

Published in Journal of the American Chemical Society 98:23 (November 10, 1976), pp 7189-7191.

Submitted March 15, 1976. 
The impact energies at which the resonant structures are observed yield the magnitudes ${ }^{2}$ of the gas-phase electron affinities (EA). In this communication we report the electron affinities of the above listed benzene derivatives determined by means of electron transmission spectroscopy (ETS). ${ }^{3-4}$

In Figure 1, we present the electron transmission spectra 5 of benzene, phenol, fluoro-, and chlorobenzene. The structure in the benzene spectrum, which is in good agreement with that found by others, ${ }^{3 b, 3 c, 6}$ corresponds to the capture of an incident electron into the doubly degenerate $\mathrm{e}_{2 \mathrm{u}}\left(\pi^{*}\right)$ orbital, yielding the $\mathrm{X}^{2} \mathrm{E}_{2 \mathrm{u}}$ ground electronic state of the benzene anion. ${ }^{7}$ The lifetime of the anion is sufficiently long that a progression of vibrational levels of the symmetric breathing mode is observed. ${ }^{8}$ With substitution on the ring, the degenerate $\mathrm{e}_{2 \mathrm{u}}\left(\pi^{*}\right)$ orbital splits into $b_{1}\left(\pi^{*}\right)$ and $a_{2}\left(\pi^{*}\right)$ orbitals. ${ }^{9}$

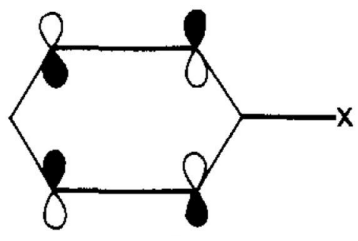

$\mathrm{a}_{2}\left(\pi^{*}\right)$

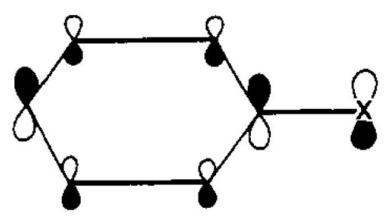

$\mathrm{b}_{1}\left(\pi^{*}\right)$

This splitting is particularly evident in the transmission spectrum of phenol. Similar results were found in aniline and anisole and the spectra are not shown. As shown below, the $\mathrm{a}_{2}\left(\pi^{*}\right)$ orbital has nodes on the 1 and 4 carbons, while the $b_{1}\left(\pi^{*}\right)$ orbital does not possess nodes on any of the carbons.

The $-\mathrm{NH}_{2},-\mathrm{OH}$, and $-\mathrm{OCH}_{3}$ groups have small positive inductive effects $^{10}$ (which stabilize both $\mathrm{A}_{2}$ and $\mathrm{B}_{1}$ anion states) and large negative resonance effects ${ }^{10}$ (which destabilize the $B_{1}$ state). We expect, therefore, that the ground state anions of aniline, phenol, and anisole will be slightly more stable than the ground state of $\mathrm{C}_{6} \mathrm{H}_{6}{ }^{-}$and will be of $\mathrm{A}_{2}$ symmetry. On the other hand, the second anion states denoted by $\widetilde{\mathrm{A}}{ }^{2} \mathrm{~B}_{1}$ should lie well above the $\mathrm{C}_{6} \mathrm{H}_{6}{ }^{-}$ground state. The electron transmission spectra illustrate nicely the role of inductive and resonance contributions to anion stabilities. While the first EA of benzene is $-1.15 \mathrm{eV}$, the first two EA's are -1.13 and $-1.77 \mathrm{eV}$ for aniline, -1.01 and $-1.81 \mathrm{eV}$ for phenol, and -1.00 and $-1.63 \mathrm{eV}$ for anisole. The $\widetilde{\mathrm{X}}^{2} \mathrm{~A}_{2}$ states of $\mathrm{C}_{6} \mathrm{H}_{5} \mathrm{OH}^{-}$and $\mathrm{C}_{6} \mathrm{H}_{5} \mathrm{OCH}_{3}{ }^{-}$are lower than 


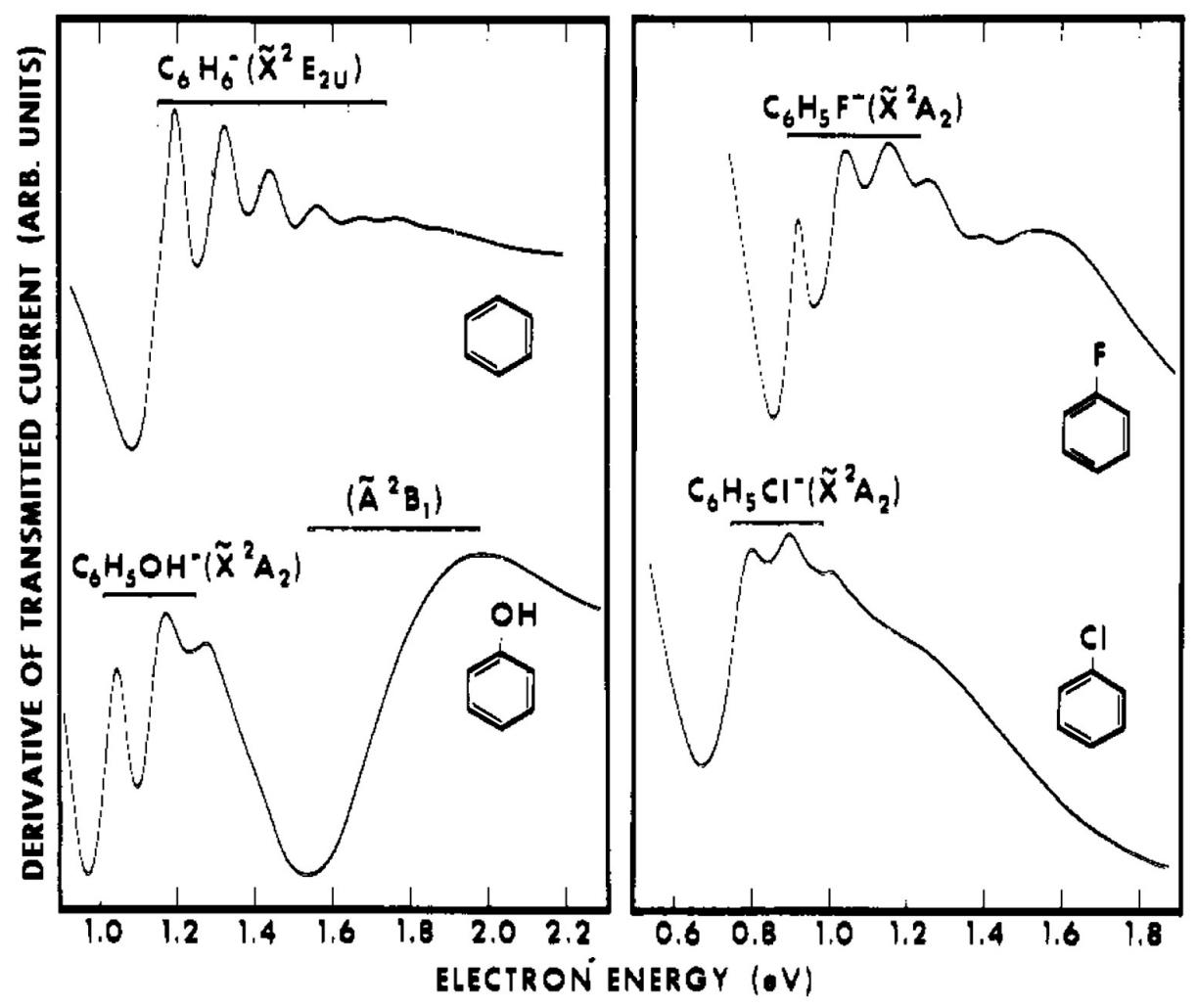

Figure 1. The derivative of the transmitted current as a function of electron impact energy in benzene, phenol, fluoro-, and chlorobenzene.

that of $\mathrm{C}_{6} \mathrm{H}_{5} \mathrm{NH}_{2}{ }^{-}$corresponding to the greater inductive effects of the $-\mathrm{OH}$ and $-\mathrm{OCH}_{3}$ groups relative to the $-\mathrm{NH}_{2}$ group. The $\widetilde{\mathrm{A}}{ }^{2} \mathrm{~B}_{1}$ state of $\mathrm{C}_{6} \mathrm{H}_{5} \mathrm{NH}_{2}{ }^{-}$lies above those of $\mathrm{C}_{6} \mathrm{H}_{5} \mathrm{OH}^{-}$and $\mathrm{C}_{6} \mathrm{H}_{5} \mathrm{OCH}_{3}^{-}$, consistent with the greater resonance contribution of the $-\mathrm{NH}_{2}$ group. These symmetry assignments were confirmed for phenol by means of a SCF-MO calculation. ${ }^{11}$ The ground states of the temporary anions exhibit welldefined vibrational structure, ${ }^{12}$ thus allowing an accurate determination of the adiabatic EA's of each of the gases..$^{13}$ The excited states of the anions are apparently shorter lived and do not display measurable vibrational structure. We characterize the energy of these states by that of the midpoint of the structure. This energy corresponds to the negative of the vertical EA.

Although the fluoro, chloro, and bromo substituents also possess positive inductive and negative resonance effects, ${ }^{10}$ induction is considerably more important for the halogens than for $-\mathrm{NH}_{2},-\mathrm{OH}$, and 
$-\mathrm{OCH}_{3}$. We expect, therefore, that the ground-state anions of $\mathrm{C}_{6} \mathrm{H}_{5} \mathrm{~F}$, $\mathrm{C}_{6} \mathrm{H}_{5} \mathrm{Cl}$, and $\mathrm{C}_{6} \mathrm{H}_{5} \mathrm{Br}$ will be significantly stabilized relative to the $\mathrm{C}_{6} \mathrm{H}_{6}{ }^{-}$ ground state. This is indeed the case. The first EA's for these three halobenzenes are $-0.89,-0.75$, and $-0.70 \mathrm{eV}$, respectively. The latter two values are in good agreement with those reported by Nenner and Schulz ${ }^{3 \mathrm{C}}$ using ETS. ${ }^{14}$ The energies of the second anion states of the halobenzenes cannot be determined accurately to be substantially shorter than those of the ground states and the associated spread in energy is sufficiently large to mask the splittings, which we anticipate to be $\sim 0.2-0.4 \mathrm{eV}$. A portion of the structure ascribed to a second anion state appears most visibly in $\mathrm{C}_{6} \mathrm{H}_{5} \mathrm{~F}$. With $\mathrm{C}_{6} \mathrm{H}_{5} \mathrm{Cl}$ this feature appears to broaden and disappears completely in $\mathrm{C}_{6} \mathrm{H}_{5} \mathrm{Br}$. The spectra also suggest a progressive shortening in lifetime of the ground-state anions along the substituent sequence $\mathrm{F}, \mathrm{Cl}$, and $\mathrm{Br}$.

Dissociative attachment under electron impact according to the reaction

$$
\mathrm{C}_{6} \mathrm{H}_{5} \mathrm{X}+\mathrm{e}^{-} \rightarrow \mathrm{C}_{6} \mathrm{H}_{5} \mathrm{X}^{-} \rightarrow \mathrm{C}_{6} \mathrm{H}_{5}+\mathrm{X}^{-}
$$

is energetically possible for $\mathrm{C}_{6} \mathrm{H}_{5} \mathrm{Cl}$ and $\mathrm{C}_{6} \mathrm{H}_{5} \mathrm{Br}$ throughout the range of electron energies employed in our investigation. ${ }^{15}$ Experimental studies ${ }^{16}$ have been performed which show that the $\mathrm{Cl}^{-}$and $\mathrm{Br}^{-}$production is maximum near electron energies of 0.86 and $0.84 \mathrm{eV}$, respectively. We suggest that dissociative attachment will proceed primarily from the $\widetilde{\mathrm{A}}{ }^{2} \mathrm{~B}_{1}$ states rather than the $\widetilde{\mathrm{X}}^{2} \mathrm{~A}_{2}$ states, since the $\mathrm{b}_{1}\left(\pi^{*}\right)$ orbital is antibonding between the halogen and the ring. It is important to note that the short lifetimes $\left(1 \mathrm{O}^{-15} \mathrm{~s}\right)$ of $\mathrm{C}_{6} \mathrm{H}_{5} \mathrm{Cl}^{-}$and $\mathrm{C}_{6} \mathrm{H}_{5} \mathrm{Br}^{-}$are due to electron autodetachment and not to dissociative attachment, which takes place on a longer time scale.

To summarize our results, in Table I we list the electron affinities of the molecules studied in this paper. For comparative purposes we have listed our earlier results for toluene. ${ }^{1}$ We have also included the third electron affinities associated with capture of an electron into the $b_{1}\left(\pi_{3}{ }^{*}\right)$ orbitals of the substituted benzenes and the $b_{2 g}\left(\pi_{3}^{*}\right)$ orbital of benzene. ${ }^{3 b}$ For each of the molecules studied, the third electron affinity lies between -4.45 and $-5.12 \mathrm{eV}$. The relative positions are in accord with our earlier discussion of inductive and resonance effects.

To provide an overview of the effects of substitution on the unfilled as well as filled orbitals, we present in Figure $\mathbf{2}$ a correlation diagram of the anion and cation states. For the latter, the splitting of 
Table I. Electron Affinities (eV) of Benzene and Monosubstituted Benzenes

\begin{tabular}{lccc} 
Compound & $\begin{array}{c}\text { First EA } \\
\left(\pi_{1}^{*}\right)^{a}\end{array}$ & $\begin{array}{c}\text { Second EA } \\
\left(\pi_{2}{ }^{*}\right)^{b}\end{array}$ & $\begin{array}{c}\text { Third EA } \\
\left(\pi_{3}{ }^{*}\right)^{b}\end{array}$ \\
\hline Benzene & -1.15 & -1.15 (degenerate) & -4.85 \\
Fluorobenzene & -0.89 & Not observed & -4.77 \\
Chlorobenzene & -0.75 & Not observed & -4.50 \\
Bromobenzene & -0.70 & Not observed & -4.42 \\
Phenol & -1.01 & -1.73 & -4.92 \\
Anisole & -1.09 & -1.72 & -4.92 \\
Aniline & -1.13 & -1.85 & -5.07 \\
Toluene & -1.11 & No splitting & -4.88
\end{tabular}

a. Determined from the zeroth vibrational level of the ion. The error in these values is less than $\pm 0.05 \mathrm{eV}$.

$b$. Vibrational structure is not observed in the second and third negative ion states. The energies are determined from the center of the structure in the cross section. The error in these values is estimated to be $\pm 0.08 \mathrm{eV}$.

c. Reference 1.



Figure 2. Correlations between the EA's and IP's of monosubstituted benzenes. 
the $e_{1 g}(\pi)$ orbital of benzene into the $b_{1}(\pi)$ and $a_{2}(\pi)$ orbitals has been the subject of several investigations ${ }^{17}$ employing photoelectron spectroscopy. We have not indicated the positions of the third ionization potentials since, for some of the substituted benzenes, the assignment is still open to question.

These studies indicate that ETS provides a complement to photoelectron spectroscopy in yielding information about the shifts of levels due to substituent effects. Although the shifts in anion energies can be interpreted in terms of the same concepts invoked for cation states, the variations in anion lifetime are poorly understood and warrant further investigation.

Acknowledgment We acknowledge support from the donors of the Petroleum Research Fund, administered by the American Chemical Society.

\section{References and Notes}

(1) K. D. Jordan, J. A. Michejda, and P. D. Burrow, J. Am. Chem. Soc., 98, 1295 (1976).

(2) The sign of the electron affinity is taken by convention to be negative for an unstable anion.

(3) (a) L. Sanche and G. J. Schulz, Phys. Rev. A, 5, 1672 (1972); (b) J. Chem. Phys., 58, 479 (1973); (c) I. Nenner and G. J. Schulz, ibid., 62, 1747 (1975). These references contain a detailed discussion of electron transmission spectroscopy.

(4) P. D. Burrow and K. D. Jordan, Chem. Phys. Lett., 36, 594 (1975).

(5) These spectra are acquired by passing a high resolution electron beam through a cell containing gas at sufficient density to scatter approximately $60 \%$ of the electron beam. The unscattered, or transmitted, portion of the beam, which is collected, is related to the total scattering cross section. To enhance the visibility of sharp variations in the scattering cross section, the derivative of the transmitted current with respect to energy is plotted as a function of the electron impact energy.

(6) M. J. W. Boness, I. W. Larkin, J. B. Hasted, and L. Moore, Chem. Phys. Lett., 1, 292 (1967).

(7) For a discussion concerning the identification of this state, see-S. F. Wong and G. J. Schulz, Phys. Rev. Lett., 35, 1429 (1975).

(8) We Infer from the characteristics of the spectra and our Instrumental energy resolution that the lifetimes of the anions studied here correspond to spreads in energy in excess of $0.04 \mathrm{eV}$. 
(9) We label the orbitals of the substituted benzenes according to the $C_{2 \mathrm{v}}$ point group.

(10) S. Ehrenson, R. T. C. Brownlee, and R. W. Taft, Prog. Phys. Org. Chem., 10, 1 (1973).

(11) The SCF-MO calculations were performed using the GAUSSIAN 70 program (available as QCPE program 236 from Indiana University) of W. J. Hehre, W. A. Lathan, R. Ditchfield, M. D. Newton, and J. A. Pople. The calculations were of the STO-3G variety. Splittings between the $\mathrm{a}_{2}\left(\pi^{*}\right)$ and $\mathrm{b}_{1}\left(\pi^{*}\right)$ orbitals of 0.39 and $0.25 \mathrm{eV}$ for phenol and fluorobenzene, respectively, were obtained.

(12) The vibrational spacing of the ground state anions of $\mathrm{C}_{6} \mathrm{H}_{5} \mathrm{OH}, \mathrm{C}_{6} \mathrm{H}_{5} \mathrm{OCH}_{3}$, $\mathrm{C}_{6} \mathrm{H}_{5} \mathrm{NH}_{2}, \mathrm{C}_{6} \mathrm{H}^{5} \mathrm{~F}, \mathrm{C}_{6} \mathrm{H}_{5} \mathrm{Cl}$, and $\mathrm{C}_{6} \mathrm{H}_{5} \mathrm{Br}$ is $12 \mathrm{O}, 125,12 \mathrm{O}, 115,125$, and $\sim 125 \mathrm{meV}$, respectively. Of the modes which are energetically possible, we favor the $\mathrm{a}_{2}\left(\mathrm{v}_{17 \mathrm{a}}\right)$ ring puckering vibration. The excitation of this mode is consistent with the charge distribution of the $\mathrm{a}_{2}\left(\pi^{*}\right)$ orbital.

(13) The existence of temporary anion states in benzene and certain of its derivatives was first inferred by R. N. Compton, L. G. Christophorou, and R. H. Huebner, Phys. Lett., 23, 656 (1966), using the $\mathrm{SF}_{6}$ electron scavenger technique. The splitting of the degenerate benzene anion states under substitution was studied by L. G. Christophorou, D. L. McCorkle, and J. G. Carter, J. Chem. Phys., 6o, 3779 (1974), using the trapped electron method. Neither of these techniques is sensitive to sharp structure in the scattering cross section and thus only a rather crude bound on the EA's can be determined in general. Furthermore, signals arising from direct vibrational excitation may also be present. The results described in the latter reference are not In good agreement with those of the present work nor are they consistent with known resonance and induction effects.

(14) I. Nenner and G. J. Schulz reported only a bound for the EA of $\mathrm{C}_{6} \mathrm{H}_{5} \mathrm{~F}$ of $>-1.0 \mathrm{eV}$.

(15) $\mathrm{In}_{6} \mathrm{H}_{5} \mathrm{~F}$, the onset for this process is about $1.55 \mathrm{eV}$.

(16) L. G. Christophorou, R. N. Compton, G. S. Hurst, and P. W. Reinhardt, J. Chem. Phys., 45, 536 (1966).

(17) D. W. Turner, C. Baker, A. D. Baker, and C. R. Brundle, "Molecular Photoelectron Spectroscopy”, Wiley-lnterscience, New York, N.Y., 1970, and references cited therein. 